\title{
Science Academies' Refresher Course on Classroom Chemistry - Concepts and the Curiosities
}

\author{
organised by \\ Department of Chemistry (UG and PG) \\ Jhargram Raj College (Govt. of West Bengal) \\ Jhargram 721507, West Bengal \\ 6 December 2018 - 20 December 2018 \\ Sponsored by \\ Indian Academy of Sciences, Bengaluru \\ Indian National Science Academy, New Delhi \\ The National Academy of Sciences, India, Allahabad
}

\begin{abstract}
A Refresher Course in 'Class Room Chemistry-Concepts and the Curiosities' for College/University teachers/research scholars will be held at the Department of Chemistry (UG and PG), Jhargram Raj College (Govt. of West Bengal) Jhargram 721507, West Bengal during December 06-20, 2018. The Course is primarily aimed at teachers involved in teaching various disciplines in Chemical Sciences at the UG/PG level, although a few seats will be available for research scholars/post-docs in Chemical Sciences. The Course will cover the basic and advanced contemporary topics of the subject incorporated in Choice Bases Credit System (CBCS) recently implemented by the UGC through lectures and tutorials. College/University teachers having at least a Master's degree in Chemistry are particularly encouraged to apply. Topics to be covered include Green chemistry, Advanced Synthetic Organic Chemistry, Stereochemistry, Asymmetric Synthesis, Photochemistry and Pericyclic Reactions, Organometallic Chemistry, Bio-inorganic Chemistry, Biophysical Chemistry, Supramolecular Chemistry and Crystal Engineering, Soft Material, Isoreticular Chemistry (CP, MOF, COF), Material Chemistry and Nanotechnology, X-Ray Crystallography, Quantum Chemistry and Molecular Spectroscopy, Modern Spectroscopic and other analytical methods. The UGC has approved the Academies' sponsored two-week Refresher Courses for promotion through the CAS, vide notification. F3-1/2009 dated 30 June 2010.
\end{abstract}

Resource Persons: Prof. Brindaban Chandra Ranu (IACS Kolkata), Prof. Parthasarathi Dastidar (IACS Kolkata), Prof. Amit Basak (IITKGP), Prof. Swagata Dasgupta (IITKGP), Prof. Sabyasachi Sarkar (IIEST, Shibpur), Prof. Ashutosh Ghosh (CU, Kolkata), Prof. Nitin Kumar Chattopadhyay (JU), Prof. Dulal Chandra Mukherjee (CU, Kolkata), Prof. Sanjib Bagchi, Burdwan University.

A maximum of 45 applications will be considered. Teachers who wish to participate in the Refresher Course may apply through proper channel with the following details: name, date of birth, gender, e-mail, official and residential addresses, telephone numbers, academic qualifications, courses taught, affiliation, positions held and tenure. It is also essential to submit a brief statement (between 250 and 500 words) as to why they think the Course will help to improve their classroom teaching of Chemical Science.

Applications should be submitted ONLINE by clicking the following link:

http://web-japps.ias.ac.in: 8080/Refreshcourse/PBP.jsp

A printed copy of the application approved by the Head of the institution (or competent authority) should be sent by speed post to the Coordinator: Dr Tapas Kumar Adalder, Department of Chemistry (UG and PG), Jhargram Raj College, Jhargram 721507, West Bengal latest by November 20, 2018.

Scanned copies may be sent by Email to tapasadalder@gmail.com. Outstation candidates will be provided local hospitality and round-trip bus/train (three-tier AC) fare by the shortest route. Please note that participants must arrive on December 05 and leave on December 20, 2018.

Course Director: Prof. Brindaban Chandra Ranu, FNA, FASc, JC Bose National Fellow, IACS Kolkata

Course Coordinator: Dr Tapas Kumar Adalder, Department of Chemistry (UG and PG), Jhargram Raj College.

Email: tapasadalder@gmail.com; Contact Number: 09836018895/8968579241

Last date for receipt of applications: 20 November 2018 